\title{
Folklore cigüeñil
}

\section{INTRODUCCIÓN}

Pocos animales silvestres se han mantenido tan en el centro de la atención humana como la cigüeña. Las más antiguas civilizaciones se desarrollan dentro del área que todavía hoy ocupa uno de los núcleos poblacionales del ave: Anatolia y Mesopotamia. Otro núcleo, hoy mucho más extenso, cubre el Centro, Sur-este y parte del Este de Europa. De este segundo núcleo constan fehacientes testimonios en la antigua literatura helénica y latina, y es el que, más tarde, durante la Edad Media, motiva considerable desarrollo folklórico cigüeñil entre las naciones germánicas y eslavas. Existen hoy otros dos núcleos poblacionales importantes: uno en la Península Ibérica y otro en Berbería. Este último está menos estudiado en lo folklórico: es geografía que lleva doce siglos sumida en la cultura del Islam, donde el ave a veces se sacraliza o, al menos, suele gozar de gran respeto. Existe allí la creencia de que las cigüeñas reencarnan hombres difuntos, un tema que luego abordaremos. Cuenta el zoólogo Angel Cabrera ${ }^{1}$ que a comienzos de nuestro siglo había en la ciudad de Fez un hospital dedicado a recoger cigüeñas heridas, enfermas o caídas del nido. Las cigüeñas, junto con los marabús, el pico-zapato y otras grandes Cicónidas, se designan en árabe genericamente como "abú", que significa padre. Creen los musulmanes que la cigüeña es otro peregrino que va a La Meca, de aquí su calificativo vernacular "hadchi-laklak", que quiere decir "cigüeña peregrina".

Antes de entrar más en materia, conviene recordar qué tipo de relaciones establecen o establecieron por doquier la cigüeña y el hombre.

La ligazón más espectacular del ave con nosotros, surge al elegir ésta sitios o sustratos para emplazar sus voluminosos nidos. En muchos países la gran mayoría de nidos quedan sobre edificios. Puede verse, por ejemplo, la estadística de nidotópica de 8.549 nidos españoles en la tabla II.1 de mi estudio de $1981^{2}$. Hay también muchos nidos en árboles, pero en todo

\footnotetext{
1 Historia Natural (Barcelona: Inst. Gallach, 1925), tomo I.

2 Francisco BERNIS, La población de las cigüeñas españolas. 1948-1974 (Madrid, 1981). Edición depositada en la Sociedad Española de Ornitología.
} 
caso el ave propende claramente a buscar la contigüidad o cercanía de establecimientos humanos.

No menos importante es la ligazón de la cigüeña al campo agrícola y al ambiente pastoril, cuando llega su hora de comer. Sigue fielmente al arado (hoy al tractor) dondequiera que el hombre trabaje la tierra, completando así con mínimo esfuerzo su dieta a base de lombrices, larvas, grillos y demás animalículos minadores que las rejas desentierran.

Una vez recogidas las mieses, la cigüeña frecuenta y bate los rastrojos, $\mathrm{y}$, en todo tiempo, pero más en verano, trasiega los pastizales para engullir sobre todo saltones, langostas y escarabajos. En los oasis y en los valles con regadío el ave depende bastante de la actividad regante del agricultor. Sin embargo, aunque los animalículos artrópodos e invertebrados constituyen a menudo la biomasa principal que el ave consume, el hombre se fijó siempre más en su captura de animales mayores, tales como batracios, serpientes y otros reptiles que ve al ave atrapar en los campos y luego aportar a sus pollos en el nido.

Una tercera y no desdeñable relación de ave y hombre, viene de la clase de material que aquélla utiliza para construir los nidos: sarmientos, leña fina, paja, estiércol, sogas, papeles, trapos e incluso la más variada gama de prendas de vestir, algunas de ellas muy íntimas, que "roba" de suelos y tendederos.

El hombre, por su parte, admite ingenua o fundadamente que la cigüeña es un zoófago beneficioso para el campo y para el hombre mismo. El beneficio del campo se justifica por el gran número de larvas e insectos que devora, entre estos muy particularmente saltones y langostas. En cambio, el supuesto beneficio para el hombre se infiere de la eliminación de "sabandijas", vago término de muy antiguo uso, que incluye abigarrada mezcla de animales repulsivos, desagradables y peligrosos. Las raíces de esa cultura popular de aversión y temor surgen con el terror de las gentes a las serpientes en general y a las víboras y otras venenosas en particular, un terror que seguramente estuvo bien desarrollado entre nuestros antepasados cazadores del paleolítico, heredado en ellos, a su vez, de los primeros hombres-monos. La reacción instintiva de terror y agresión a las serpientes es bien conocida en macacos y otros primates, así como también en diversos mamíferos carnívoros y en ciertas aves. La paleontología demuestra que el surgir y la diversificación de las serpientes venenosas coincide con el moderno (terciario) boom de animales de sangre caliente, especialmente mamíferos pequeños y medianos.

A la postre, no solo la cigüeña busca al hombre, sino que también el hombre busca a la cigüeña. En una gran parte de Europa central y oriental, la oferta de estructuras para nido está y estuvo enormemente extendida. 
No encuentro alusión a nidos artificiales en autores clásicos. Podría pensarse que esta costumbre se desarrollara sobre todo a lo largo de la Edad Media. En 1555, Pierre Belon, de regreso en Francia después de su famoso largo viaje por el cercano Oriente, dice que las cigüeñas son aves bien conocidas en todo el mundo, pues les acondicionan a menudo ruedas sobre las cúspides de los palacios de las villas ${ }^{3}$.

\section{El falso CANTO DE LA CIGÜEÑa}

La cigüeña no tiene voz. El ruidoso crotoreo que emite se produce al entrechocar ambas mandíbulas. Se trata de una manifestación acústica que encaja ritualmente en la ceremonia de rechazo de rival, de autoafirmación de propiedad de nido, y de contacto o reconocimiento entre las dos cigüeñas cónyuges. Tal pauta conductual no solo es muy sonora, sino además enormemente espectacular, algo que siempre impresionó al hombre de a pie que mira a las aves ejecutantes posadas en las alturas de cara a los cielos. El crotoreo se despliega en varias fases: en una de ellas el ave lanza el pico hacia arriba y luego hacia atrás, para volver una y otra vez a su cayente posición delantera con aleteo bombeado. Todo eso sugiere analogía con el braceo y las reverencias de sacerdotes que invocan a la divinidad. El despliegue crotoreal de la cigüeña fue interpretado por los germanos como prueba de adoración y agradecimiento del ave hacia los dioses. No cabe duda de que por ahí le vino al ave cierto atributo de animal divino. Hasta hace poco, los crotoreos de la cigüeña al caer la tarde se tomaban en el valle suizo de Aare como otra oración de Angelus.

Escribe Ovidio: "Ipsa sibi plaudat, crepitante ciconia rostro". Y San Isidoro nos dice "ciconiae quasi cicaniae a sono quo crepitant dicta sunt", en donde se implica el verbo latino canere y se da una explicación onomatopéyica del vernáculo latino del ave ${ }^{4}$, del cual deriva nuestro "cigüeñan y otros apodos del animal en las diferentes lenguas romances. Claramente onomatopéyico es el nombre que recibe el ave en árabe clásico: "laklaka" que vemos en uso por El Magreb. Pero lo más sorprendente es leer que en inscripciones mesopotámicas del período sumerio-acádico, hace más de cuatro mil años, se puede reconocer la palabra "lakalaka" atribuible a un ave que es con toda probabilidad nuestra cigüeña ${ }^{5}$.

\footnotetext{
3 Pierre BELON, L'Histoire de la Nature des Oyseaux, 1555.

4 SAN IsIDORO, Origines sive etymologiae.

5 Cita de SALONEN en E. SCHÜZ, *Die Namen des Weiss Storchs als Ausdruck einer vielfältigen Mensch Vogel Bezienhung*, B. Veröff. Nat. Baden Württemberg (1986), 15-24.
} 
Nuestro Gerónimo Huerta ${ }^{6}$ recoge la antigua frase latina aglotorat immenso de turre ciconia rostron, y al explicar el batir del pico añade que a eso llaman "crepitar", vocablo de culto aroma, que no vemos hoy usado entre el paisanaje español, el cual dice "machacar el ajo" o "hacer el gazpacho" de la emisión sonora del ave. El citado Huerta, al reconocer que la cigüeña carece de voz, comenta que algunos creen el ave no tener lengua, pero "yo he visto - dice- ser esto falso, aunque en verdad ser pequeñan.

\section{SACRALIZACIÓN Y VENERACIÓN}

Dice Philostratos que los antiguos adoraban tanto a las cigüeñas, que cuando cada año veían la primera se hincaban de rodillas?.

Los germanos vieron en este ave al mensajero de los dioses, encargada de anunciar la nueva vida tras el desabrido y oscuro invierno.

Aristóteles, en su Historia de los Animales, informa de que las cigüeñas recibían grande honra en la Tesalia por destruir serpientes, y que al que mataba una de estas aves se le aplicaba igual pena ${ }^{8}$. El mismo dato repite siglos después Plinio el Viejo en su Historia Natural ${ }^{9}$, y desde este autor pasa a los polígrafos naturalistas del siglo XVI.

Belon ${ }^{10}$ en sus Singularitez advierte que las cigüeñas son queridas de los egipcios por mantener a raya las ranas y serpientes. El mismo autor, en su Histoire de la Nature des Oyseaux ${ }^{11}$, exhibe una figura de cigüeña que porta la serpiente en el pico. La enorme estimación de los egipcios por el ave convertía en grandísimo delito el ofenderla, dato comentado en glosa de Gerónimo Huerta como traductor de Plinio. Dice de su cosecha Huerta que la cigueña se alimenta de "serpientes, lagartos, ranas y otras sabandijas venenosas" ${ }^{12}$.

La veneración a la cigüeña prosigue durante la Edad Media y comienzos de la Moderna, pero no solo como destructora de sabandijas, sino

6 Anotaciones en su traducción de Plinio, 1624.

7 Cita en O. Keller, Die Antike Tierwelt (Leipzig, 1913).

8 Historia Animalium. Ed. bilingüe latín-inglés (Londres, 1965-70).

9 Historia Natural (Madrid, 1624). Traducción de Gerónimo Huerta. Consultada también la edición latina, Naturalis Historiae, de I. DeLECHAMPIUS.

10 Pierre Belon, Les observations du plusieurs singularitez... (viajes por Grecia, Egipto y Asia Menor), 1553.

11 Op. cit.

12 Anotaciones, op. cit., 1.c. 
también como portadora de atributos excepcionales: adivina, mensajera de la divinidad, concesionaria de suertes y bienes o protectora frente a desgracias, según se irá viendo a continuación.

Muy interesante para nosotros es el siguiente pasaje tomado del libro de un soldado que llega a capitán en el ejército de Napoleón (J.-R. Coignet) ${ }^{13}$ : "Entramos en España por el Puente de Irún. Algunos de nuestros camaradas habiendo hallado un nido de cigüeña se apresuraron a destruirlo cogiendo los dos pollos que contenía. Inmediatamente las autoridades del País reclamaron los cigüeños a nuestro coronel. Porfiaba el alcalde español que estas aves son veneradas en el País, que son necesarias para destruir serpientes y lagartos, y que había pena de galeras para quien las matara. En verdad estas aves se veían por doquier. Allí les ofrecen viejas ruedas sobre postes para que hagan sus nidos... Nuestro coronel, no deseando herir semejantes costumbres hizo devolver los cigüeños" ${ }^{14}$.

\section{METEMPSICOSIS}

La reencarnación de un hombre en un animal es vieja creencia entre los hindúes. Se dice todavía en la India que las ánimas de los muertos toman figura de cigüeña. Aeliano ${ }^{15}$, en el siglo II-III d.C., narra que las cigüeñas se convierten en hombres piadosos cuando marchan a las islas del Océano. Dähnhardt ${ }^{16}$ cuenta una vieja leyenda eslava según la cual Dios metió todos los reptiles en un saco cerrado que encomendó a cierto hombre para ser lanzado al mar. La curiosidad hizo que este hombre abriera el saco y los reptiles se escaparon, siéndole imposible volverlos a coger. Entonces llega Dios y le increpa: "No has cumplido mi mandato, así que te convierto en cigüeña y quedas condenado a capturar eternamente ranas, serpientes y gusanos". Según los Gattiker ${ }^{17}$ se conoce una variante de igual leyenda en que es una mujer la protagonista.

Según los citados Gattiker otras historias similares de conversión del ave en ser humano se conocen o conocieron en Bohemia, Rumanía, Polonia y Rusia Blanca. Una de las historias sobre hombre-cigüeña, recogida en la Renania, reza así: muere un conocido burgués de la ciudad y

13 J. R. CoIGNET, Vingt ans de grogne et de gloire avec L'Empereur. Obra mostrada por nuestro amigo Tato Cumming.

14 Esta y otras traducciones del presente ensayo son mías.

15 Claudio Aeliano, De Animalium Naturae. Ed. de Lión, 1562. Traducción castellana, Historia de los Animales, en editorial Gredos.

16 O. DÄHNHARDT, Natursagen (Leipzig y Berlín, 1907-1912), 4 vols.

17 E. \& L. GATTIKER, Die Vögel im Volksglauben (Weisbaden, 1989). 
esto provoca la revolución de las cigüeñas locales, que en número de 24 van a congregarse en lo alto de la torre y no dejan de crotorear durante toda la celebración del entierro. Y otra historia, también alemana, refiere que cierta persona es abordada por un desconocido que le asegura ser una de las cigüeñas que anidaba antaño en el tejado de su casa.

En igual fuente consta que en el altar mayor del Monasterio de Egmont (Flandes) se conservó una reluciente piedra preciosa, obsequio de una cigüeña a la mujer que el año antes había curado su pata y le había dado de comer hasta ser capaz de emprender el vuelo. En realidad esta historia es mucho más antigua, pues veo que narra su equivalente Aeliano de una mujer llamada Heracleis ${ }^{18}$.

\section{AVE ADIVINA, SABIONDA Y BLANCO DE AUGURES}

De veleta volante es calificada el ave en algunas comarcas alemanas, firme sobre una pata, pico a viento en su nido cimero, el pico envuelto entre las desordenadas plumas del recogido cuello, y, así estando, presiente los temporales antes de que lleguen.

La cigüeña lo sabe todo y si hablase revelaría muchos secretos de los hombres ${ }^{19}$. Creencia extendida todavía en partes de Europa es que el ave barrunta con antelación el fuego y otros desastres. Es así que en algunas localidades el casero con nido teme por su casa si ya entrada la estación la cigüeña no ha llegado todavía.

Recogen los Gattiker ${ }^{20}$ la historia de Attila, cuando asediando ya por largo tiempo la ciudad de Aquilea, donde resistían encarnizadamente los romanos, empieza a notar murmuración e inquietud entre sus huestes, llegando él mismo a dudar si levantar el sitio. Pero, de pronto, ve cómo las cigüeñas, con sus crías, abandonan la ciudad que va a ser asaltada. $\mathrm{Y}$ así, enardecidos los sitiadores, acometen y arrasan la plaza sin dejar piedra sobre piedra.

Multitud de augurios diferentes se hacen o se hacían en Alemania, Bohemia, Lituania y otros países, según que la cigüeña llegue tarde o pronto, según si llega sucia o limpia, según las posturas que adopta en el nido, según el modo de pasar volando, etc. Ver la primera cigüeña con dinero en el bolsillo, sería pronóstico de no faltar dinero el resto del año. Muchos otros pronósticos se han hecho sobre la primera cigüeña que se ve cada ano, entre ellos los favoritos de las mozas casaderas.

\footnotetext{
18 Op. cit., 1.c.

19 E. MEIER, Deutsche Sagen. Sitten und Gebräuche aus Schwaben (Stuttgart, 1862).

20 Op. cit., 1.c.
} 
Si la cigüeña deja un huevo sin incubar en el nido, alguna persona morirá en la vecindad. Si no pone ningún huevo, no nacerán niños en la casa y si mueren los pollos fallecerá alguna criatura (en Westfalia) ${ }^{21}$. Donde anidan cigüeñas caen bendiciones. Si anidan sobre casa de recién casados vendrán a la larga tantos hijos como pollos críe el ave ese año (Oldenburgo). Nido en casa nueva anuncia pronta boda (Bohemia). Si se amputa la lengua o la pata de algún pollo, el primer niño nacerá mudo o manco (Mecklenburgo) ${ }^{22}$.

Los augurios del último párrafo tienen relación con el tema siguiente.

\section{PORTADORA DE NIÑOS}

Esta enternecedora fantasía goza de firme vigencia en gran parte de Europa Central y Oriental. Parece que el foco de origen hay que buscarlo entre los germanos. Se conocen datos de su arraigo en Alemania desde hace varios siglos como mínimo ${ }^{23}$. A Suiza, Francia y otras partes del sur y sureste de Alemania, la fantasía llega más tarde, acaso no antes del siglo pasado. En el ambiente popular español no hubo nada parecido. La cigüeña como portadora de niños es en nuestro país un cultismo de muy reciente entrada que irradia a partir de clases ilustradas y que, además, viene en versión muy simplificada. Merece, pues, dar a conocer mejor este elemento del folklore cigüeñil extranjero, resumido a partir de la información suministrada en el documentado libro de los Gattiker.

De la vieja asociación entre cigüeña y Holda, diosa de la hacendosidad casera, del amor y de las buenas costumbres, derivaría la muy vieja creencia de que la cigüeña toma los niños (o sus almas) en manantiales y lagunas, y luego vuela con ellos para colocarlos en el regazo de las parturientas. Se suele representar el ave portando el bebé en el pico, suspendido de un pañal, pero en algunas zonas de Alemania la cigüeña solo trae en el pico a los niños malos, mientras que los buenos son transportados sobre las costillas. De ahí la expresión alemana aplicada a los niños traviesos: "Tus hijos no han venido a la costilla".

La tradicional conseja (Alemania, Bohemia) dice que las criaturas son echadas por la chimenea central del hogar. Los viejos nombres vernaculares centroeuropeos de la cigüeña, tales como "Adebar", "Heilebart"

${ }^{21}$ R. KUHK, "Legenden und Falschmeldungen über Störche», Vogelwarte, 17 (1954), 165-166.

22 Tres datos tomados nuevamente del libro de los GaTTIKER, op. cit.

23 Ibid. 
y sus multiples variantes dialectales, podrían llevar con la raíz "bero" o "bar", la idea de transporte. Según esta tesis, "adebar" u "odobero" significaría "portadora de ventura", pero según otra tesis "adebar" derivaría de "uda" que es pantano y "faran" (marchar). Así el vernáculo calificaría a un ave zancuda palustre, lo que le va bien a la cigüeña.

En algunas versiones, la paidofilia de la cigüeña se condimenta con el supuesto de que el ave picotea la pierna de la mujer gestante, sin duda una suave manera de aludir a la concepción. Así cuando se dice "Es hat gebracht ein Bruderlein, es hat gebissen die Mutter ins Bein". Destaca por su gracia el siguiente dicho popular en dialectal alemán antiguo: "Adebar, du goder, bring mi'n lütjen Broder, Adebar, du bester, bring mi'n lütjen Swester", del cual se conocen variantes en Westfalia, Magdeburgo, Koszalin (Polonia) y partes de Suiza. La versión que recogemos tiene como posible traducción: "Cigüeña, tú la buena, tráeme un hermano mamoncito (de teta); Cigüeña, tú la mejor, tráeme una hermana mamoncita».

\section{PROTECTORA Y CONCESIONARIA DE SUERTE O CASTIGO}

En Bélgica, Alsacia, Bohemia, Sur de Alemania, etc., creen que tener un nido en la casa trae buena suerte. Esta creencia tiene antecedentes conocidos en pasados siglos, según se ve ya con el ejemplo siguiente. En una epístola que Aeneas Sylvius dirige al cardenal St. Angeli durante el Concilio de Basilea (año 1438), al describir esta ciudad, cuenta cómo anidan las cigüeñas en los tejados y crían así sus pollos en una patria -dice- que la propia ave considera muy conveniente, y aquí añade que nadie les hace daño y que los ciudadanos suelen temer que, si les quitaran los pollos, la casa podría ser pasto de las llamas.

También en Turquía se ha creído que el que haga mal a una de estas aves, puede caer en desgracia. En Bohemia se augura enfermedad o pobreza para el dañador. La creencia de que las casas con nido quedan protegidas contra el fuego, o contra el fuego y el rayo, ha prevalecido en Alsacia, Oldenburgo, Posen, Bohemia y en la propia Anatolia. En Bohemia se llega a decir que si destruyes a la cigüeña su nido, ésta puede venir portando ascuas en el pico para incendiar la casa. En un tratadillo medieval atribuido a Schock ${ }^{24}$ cuéntase que habiendo quitado los nidos de una casa, ésta se derrumba, o que un hombre que había matado cigüeña con la cerbatana, luego padece gran pobreza. Para hacer frente a este cúmulo de creencias y supersticiones, hubo que editar en Suavia un

\footnotetext{
24 Citado en GatTIKER, op. cit.
} 
catecismo desmintiendo explícitamente que la cigüeña protege de incendios, que no aporta suerte y que tampoco castiga con desgracias. El enfrentamiento del clero con el pagano folklore es una vieja constante que languidece más y más en nuestros tiempos de modernidad. De este problema en España, he tratado en otro lugar ${ }^{25}$. Hoy aquí, todavía, cuando vecinos y ciudadanos se pasan al bando de la Administración conservacionista y del ecologismo, sigue habiendo raros frailes o clérigos que, resentidos en su derrota, procuran detractar con toda clase de argumentos al ave.

SímBOlO DE AMOR PATERNO, GRATITUD FILIAL Y FIDELIDAD CONYUGAL

Dice Plinio que las cigüeñas hijos sustentan a sus viejos padres dándoles de comer, cuando unos cuando otros. Según otra versión, también originaria de la Antigua Roma, los padres viejos, debilitados y desplumados, son rodeados por los jóvenes dispuestos en círculo, arrancándose el propio plumón para vestir a sus padres, a quienes aportan de comer e incluso prestan ayuda al emprender vuelo. Es curioso que la disposición en círculo corresponde a un momento real, muchas veces contemplado pero aquí mal interpretado, referible al adulto que acude cargado de comida para alimentar a su crecida prole, en una situación que puede parecer confusa por el barullo de batir alas y entrechoque de picos.

Dice Gerónimo Huerta ${ }^{26}$ que en la Antigua Grecia, según Aristophanes, se promulgaron las "pelargoi nomi" o leyes cigüeñiles, en que se manda a los hijos sustenten agradecidos a sus padres. Otro autor advierte que en el Antiguo Egipto la alegoría "cigüeña" significó amor filial.

También desde muy antiguo figura la cigüeña como paradigma de fidelidad conyugal. No veo recogido este modelo en varios autores clásicos que hablan de cigüeñas. Lo más antiguo que veo es la historia relatada por el greco-romano Aeliano ${ }^{27}$ en la cual consta también el severo sentido justiciero atribuido al ave. Cuenta dicho autor que cierta cigüeña hembra aprovechaba las ausencias de su macho al ir este a buscar comida, para ajuntarse con otro macho, y luego volaba a una fuente donde se lavaba la mancha de su maldad. Conocida esta conducta adulterina por el señor de la casa donde se emplazaba el nido, un día estorbó el lavatorio de la infractora, de modo que el macho conyugal conoce el engaño. A otro día

\footnotetext{
25 F. BERNIS, «Cigüeña y paisanaje en los años cuarenta", Quercus, 105 (1994), 13-18.

26 Op. cit.

27 De Animalium Naturae.
} 
acuden multitud de cigüeñas que, a picotazos, sentencian a muerte a la adúltera.

De lo que sí hay precedente más antiguo es del ajusticiamiento de una cigüeña por las otras. Cuentan los griegos, y recoge después Plinio, que en Pithonos, lugar de Asia (hoy Turquía), en ciertas llanuras que por allí se extienden, se reunen muchas cigüeñas que murmuran entre sí y resuelven que aquella que sea la última en acudir, sea despedazada. Cumplido este veredicto luego todas se van, no quedando ninguna después del 13 de agosto. Interesa advertir el elemento real que ensarta el transcrito fabuloso pasaje, el cual describe una típica congregación premigratoria bien fechada.

El paradigma de la fidelidad conyugal y del ajusticiamiento se trasmite después en Europa de autor en autor durante la Edad Media y hasta muy entrada la Edad Moderna, recogiendo a veces punto por punto todo el contenido del pasaje de Aeliano. Es la "ciconia propter adulterium occisa". $\mathrm{Y}$ ha sido tal el convencimiento de las gentes que incluso se practican experimentos intentando su demostración, consistentes en poner un huevo de ganso o gallina en el nido de la cigüeña que incuba, para notar (así se supuso ingenuamente) que al nacer el espúreo hijo, el padre conyugal rechazaría o mataría por sí solo o con el concurso del jurado cigüeñil a la infeliz presunta adúltera. Relatos similares recogen los Gattiker ${ }^{28}$ en Cysat (1613) y en Sebillot (1904), mientras que Kuhk ${ }^{29}$ comenta los de Heisterbach (1220), Devoe (1947) y el del contemporáneo André Maurois (1953). El supuesto ajusticiamiento de cigüeñas por cigüeñas se dice haber sido observado recientemente, poco antes de la Primera Guerra Mundial, por un zoólogo, el Dr. Milewski, hallándose éste en la Masuria (al noreste de Alemania), cuando, oculto él entre malezas, vio cómo en una copiosa congregación de aves, se dedican todas a picotear inmisericordes a varias de ellas. Podría aceptarse la realidad de una agresión de aves contra aves, pero sorprende la ingenua y anacrónica interpretación que da un observador ilustrado en pleno siglo Xx.

A propósito de pelea, cabe recordar uno de los cuentos más fantásticos que sobre cigüeñas se hayan escrito. Me refiero al relato del antiguo griego Kiranides ${ }^{30}$ : Las cigüeñas que regresan de Egipto, Libia y Siria, al llegar a Licia (hoy Turquía), unidas a los pelícanos, libran feroz batalla contra cuervos, cornejas, grajos y avestruces, quedando el campo cubierto de plumas y cadáveres y un vecino río enrojecido por la sangre. Los licios

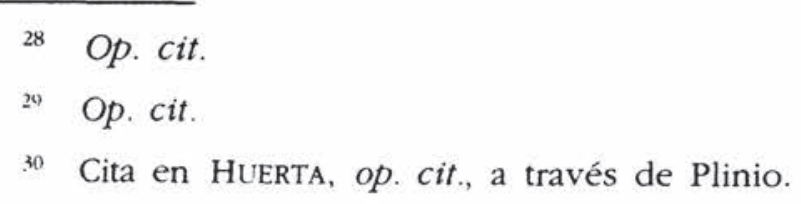


recolectan luego las plumas caídas para rellenar sus colchones y almohadas. La base real de este relato es un desplumadero en época de muda donde se producen agregaciones de aves, lo demás pura fantasía y exageración.

\section{OTRAS CREENCIAS}

Mucho más podría comentarse sobre cuentos y dichos de cigüeñas, pero solo me referiré a ciertas creencias relacionadas con la conducta reproductora del ave. Raros animales silvestres, si alguno, han puesto toda su vida privada tan a la vista y tan a mano como la cigüeña. La visión inquisitorial del hombre no se ha perdido ripio: llegada al nido, construcción de éste, cortejo, copulación conyugal, puesta, incubación, crianza... nada escapó a la indiscreta mirada humana. Pero, curiosamente, a pesar de disponerse de una información tan íntima y directa, la interpretación de todos esos sucesos a nivel popular fue y sigue siendo a menudo errónea.

Con ocasión de la encuesta que realizamos en Espana en 1948, se vio ya que estaba muy arraigada la creencia de que el ave pone tres huevos, a pesar de que el número más frecuente es cuatro. Quedó como muy general convencimiento que pone tres huevos y cría solo dos pollos (numerosas contestaciones de once diferentes provincias). Esas y otras combinaciones de huevos y pollos pueden ser reales, pero no encajan en la estadística. La pérdida de algún huevo, por huero o por rotura es frecuente, y también la de algún pollo que se retrasa o debilita a lo largo de la crianza. Es interesante advertir las explicaciones populares de esos acortamientos de huevos o pollos. En la citada encuesta hubo contestaciones afirmando que de tres huevos tiran uno para criar los dos pollos; o bien que de tres huevos sacan tres pollos pero luego tiran un pollo; o bien que si sacan más de dos pollos tiran uno; o bien que ponen número impar y crían número par. En ese "tirar" popular subyace la ingenua idea de voluntad o propósito. Un pueblo de Zamora dice que el pollo es tirado justo el día de San Juan. Varias contestaciones de la encuesta suponen que de los dos huevos que quedan, uno es macho y el otro hembra. Cabe recordar que en el siglo XVI-XVII nuestro compatriota Gerónimo Huerta no recoge ninguna de esas creencias y se limita a decir que la cigüeña pone tres o cuatro huevos que incuba durante 30 días.

Un segundo tipo de creencia tan ingenua como errónea apareció en nuestra encuesta: la de que al año siguiente vuelven al nido los hijos, pero no los padres. En años posteriores a la encuesta hemos tomado muchas 
veces de boca de las gentes esta misma creencia, al recorrer las zonas cigüeñeras españolas. En un pueblo de Cáceres dicen que los padres mueren en la costa después de atravesar el mar. Nada dice Huerta en sus glosas a la traducción de Plinio, sobre las comentadas creencias populares. Su explicación se ajusta bastante a la realidad: dice que las cigüeñas no olvidan el nido y vuelven a otro año a él, y que cada vez que vuelven limpian y reparan su construcción. Añade que la cigüeñas nuevas que no han criado todavía, no usurpan el nido de las antiguas y van a buscar lugar de acomodo distante donde edificar y componer un nido nuevo.

En Europa Central hay o hubo creencias comparables que brevemente revisaremos. $\mathrm{Al}$ año 1245 corresponde la siguiente transcripción del libro de Alberto Magno ${ }^{31}$ : "Dado que la cigüeña genera tantos pollos que no puede a todos bien mantener, expulsa uno del nido, y esto, cree el vulgo sea el pago del alquiler que el ave abona al dueño de la casan. El mismo dato es recogido por Huerta sin indicar procedencia, y Huerta añade que "algunos creen que deja ese pollo como diezmo para Dios", lo que probablemente se refiere a la España de su tiempo. En varias regiones de Alemania se sigue diciendo que la cigüeña, como ave agradecida, paga inquilinato al casero por regentar un nido en su casa. Una de las versiones de esta creencia es que el primer año paga con pluma, el segundo con huevo, y el tercero con pollo. Pero en Mecklenburgo dicen que mientras deja pluma, es buena suerte, pero la dejación de huevo y pollo en los dos años siguientes podría acarrear desgracia ${ }^{32}$.

Hoy sabemos que la cigüeña no mata ni expulsa a ninguno de sus pollos mientras éste conserve su vitalidad. Lo que ocurre es que el último pollo en nacer, y en años malos incluso otro más, se debilita por insuficiente aporte de comida que vorazmente toman el pollo o pollos mayores, y al morir o estar moribundo se convierte en un mero objeto que es expulsado y a veces engullido por un progenitor. Esta nada rara conducta real, es lo que el ornitólogo Schüz (máximo experto en cigüeñas) designó como "cronismo", de Cronos, dios que devoraba a sus hijos.

\section{CIGÜEÑa MEDICINAL}

El aprovechamiento de la cigüeña como recurso medicinal cundió mucho en el pasado. En realidad son muchos los animales e innúmeras las plantas que desde los más remotos tiempos explora y selecciona el

\footnotetext{
31 De animalibus. Siglo XIII.

32 GaTtiker, op. cit., 1.c.
} 
hombre para extraer de ellos principios curativos, con o sin fundamento, pues la medicina ancestral quedó más o menos ligada a la magia. Ya en la Antigüedad clásica, pero luego a traves de la Edad Media, las pesquisas medicinales contribuyen a desarrollar lo que más tarde sería la zoología y botánica científicas.

En la Antigüedad clásica se usó el estómago de cigüeña como contraveneno. Varios autores, hasta bien entrada la Edad Moderna, aseguran que comiendo una vez al año cigüeño asado o cocido, tomado antes de que vuele del nido, libras para el resto del año de tus dolencias, entre las que se menciona gota, pasión de ánimo, convulsiones, ceguera, corrimiento de ojos, y otras tales. El tema medicinal de la cigüeña llena páginas enteras en los libros de naturalistas posmedievales y premodernos, y así en Gessnero ${ }^{33}$, Aldrovando ${ }^{34}$ o, después, en el propio Gerónimo Huerta. Las recetas pasan machaconamente de unos a otros autores sin modificación y vienen de autoridades en parte lejanas, que son, según casos, Galeno, Dioscórides, Traliano, Pelagonio, Fauentino o Furnerio. Una entre muchas, por ejemplo, la de tomar un pollo de cigüeña no volandero, meterle la cabeza bajo el ala, ahogarlo así bajo un colchón para luego despedazarlo, destilar las piezas en un alambique y guardar el licor resultante, destinado a ser untado junto con caldo de cangrejos en la parte paralítica del enfermo.

Infinidad de otras perrerías, seguidas de cocciones o incineraciones, servían para obtener licores, ungüentos o polvos recomendados para toda suerte de dolencias y enfermedades: artrosis, gota, mal de ojos, parálisis, cólicos, etc. Como broche final, valga todavía traer a colación aquel medicinal proceder que consistía en arrancar los tendones ("nervios") de alas y patas de una cigüeña viva, para aplicarlos a los miembros de la persona accidentada, de tal modo que sanará a condición de poner los tendones derechos del ave sobre el miembro derecho del paciente, y los izquierdos sobre el izquierdo. Práctica jocosa y horrible para nuestra contemporánea sensibilidad.

FRANCISCO BERNIS

Catedrático Emérito

Universidad Complutense de Madrid

33 C. GESSNERO, Historia animalium (Zurich, 1554), vol. 2 (Oviparia).

34 Ulyses Aldrovando, Ornithologiae, 1599-1603. Se maneja la edición de Bolonia, 1645. 
Pocos animales han generado un folklore tan extenso y variado como la cigüeña blanca. Desde al menos el inicio del Neolítico, esta ave ha desarrollado una pronunciada preferencia por anidar sobre edificios o árboles del paisaje rural o pastoril. El hombre, espectador cercano de las sucesivas manifestaciones de la intimidad del ciclo vital de la cigüeña, las interpreta unas veces de un modo animista o antropomorfo y, otras veces, con un marcado realismo. También se da el caso de que manifestaciones aparentemente obvias reciban una interpretación popular totalmente incorrecta. El propósito de este estudio es dar a conocer a los lectores españoles el folklore europeo sobre la cigüeña, tal como se recoge en la bibliografía alemana. El folklore español ya ha sido discutido en otro artículo ya publicado.

Few wild animals have generated such a bulky of manifold folklore, as the White Stork. For a very long time, at least from the beginning of the Neolitic period, the bird has developed a pronounced nesting preference on buildings and on trees in the agricultural and pastoral landscape. As a neighburing spectator of the succesive intimate exhibitions composing the entire life cycle of the stork, man explains the facts observed sometimes animistically or anthropomorphycally, and sometimes rather realistically, but also some of the more obvious facts receive incorrect popular interpretation. Aim of the present paper is to make Spanish readers acquainted with the European stork folklore as has been recorded in german bibliography. Spanish stork folklore has been discussed in another published paper. 